\title{
A Prescriptive Approach to Qualify and Quantify Customer Value for Value- Based Requirements Engineering
}

Xinwei Zhang ${ }^{a, b^{*}}$, Guillaume Auriol ${ }^{a, b},{\text { Hakki } \operatorname{Eres}^{c} \text { and Claude Baron }}^{a, b}$

${ }^{a}$ CNRS; LAAS; 7 avenue du colonel Roche, F-31077 Toulouse Cedex 4, France; ${ }^{b}$ Université de Toulouse; UPS, INSA, INP, ISAE; UT1, UTM, LAAS; F-31077 Toulouse Cedex 4, France; ${ }^{c}$ Faculty of Engineering and the Environment, University of Southampton, Highfield, Southampton SO17 1BJ, UK

Recently, customer-based product development is becoming a popular paradigm. Customer expectations and needs can be identified and transformed into requirements for product design with the help of various methods and tools. However, in many cases, these models fail to focus on the perceived value that is crucial when customers make the decision of purchasing a product. In this paper, a prescriptive approach to support valuebased requirements engineering is proposed, describing the foundations, procedures and initial applications in the context of requirements engineering for commercial aircraft. An integrated set of techniques, such as means-ends analysis, part-whole analysis and multiattribute utility theory is introduced in order to understand customer values in depth and width. Technically, this enables identifying the implicit value, structuring logically collected statements of customer expectations, and performing value modelling and simulation. Additionally, it helps to put in place a system to measure customer satisfaction that is derived from the proposed approach. The approach offers significant potential to develop effective value creation strategies for the development of new products.

Key words: value model, requirements engineering, multi-attribute utility theory, value-focused thinking, quality function deployment.

*Corresponding author. Email: xwzhang@insa-toulouse.fr 


\section{Nomenclature}

$N$ : Number of customers

$M$ : Number of customer attributes

$Q$ : Number of engineering characteristics

$X:$ The set of customer attributes, $1, \ldots, M$

$x$ : One instance of $X$

$X_{i}$ : The $i^{\text {th }}$ customer attribute

$x_{i}$ : One level of attribute $X_{i}$

$w_{s}$ : Relative weight of customer $s$

$k$ : Multi-attribute utility normalization constant

$k_{i}$ : Multi-attribute utility scaling factor for the attribute $i$

$u(x)$ : Multi-attribute utility function

$u_{i}\left(x_{i}\right)$ : Single attribute utility function over attribute $i$

$u^{(s)}(x)$ : Multi-attribute utility function of customer $s$

$u_{G:}$ Group utility function

$A_{i}$ : The group weight of attribute $i$

$Y$ : The set of engineering characteristics, $1, \ldots, Q$

$Y_{j}$ : The $j^{\text {th }}$ engineering characteristic

$y_{i}$ : One levle of engineering characteristc $Y_{j}$

$f_{i}$ : Function between $Y$ and $X_{i}$

$O$ : The set of fundamental objectives, $1, \ldots, M$

\section{INTRODUCTION}

It is intuitively attractive for manufacturers to develop products that are of higher value ${ }^{\dagger}$ to customers, which will improve customer satisfaction and consequently increase sales. This further provides a comparative advantage to the manufactures that develop products of higher value over their competitors. Increasingly, manufactures are focusing on designing and developing value-added products in order to please customers and enhance sales, which in turn influence the manufacturer's objectives of maximizing profit, market share, stakeholder value, and employee satisfaction (Keeney 2004).

In order to achieve higher customer satisfaction levels, there are at least two important aspects to be considered. One is about what customer values. There are a plenty of definitions of customer value with their consensus and divergence (Zeithaml 1988, Keeney 1992, Keeney 2004, Woodruff 1997). The definition from (Woodruff 1997) is used in this paper, that is, customer value is a customer's perceived preference for product attributes, attribute performances, consequences of use, goals and purposes in use situation. Naturally, customer value $^{\ddagger}$ should be identified and utilized to drive the activities of product design and

${ }^{+}$In this paper, we think of value in a broad sense, including preference under certainty (value in a narrow sense) and preference under uncertainty (utility).

* It will be more attractive to express it as stakeholder value, but we limit the focus only on 
development. It is more about a subjective and human-centric process, and yet there are only a handful of analytical processes and methods available to enable modelling and simulation in terms of value (Agouridas et al. 2006, 2008, Bayus 2007, Claros Salinas et al. 2008, Griffin and Hauser 1993, Pahl and Beitz 2007, Ulrich and Eppinger 2007, Wang and Zeng 2009). Some preliminary work has been made to distinguish or measure different achievement levels of customer satisfaction (value), such as KANO model and quality function deployment (QFD) (Bayus 2007, Hauser and Clausing 1988, Bode and Fung 1998, Zhang and Chu 2009). However, they have certain shortcomings when it comes to enabling a systemic consideration of customer value.

Another aspect is about how engineers can design value-added products conforming to customer value. It demands engineers to optimize product quality and to minimize the cost of design and production with a minimum introduction time to market. Product quality, however, is highly dependent on subjective perception of customers, which is based on customer value. Designers then should design such products of those features and forms that are highly valued by potential customers (Keeney 2004). Recent research paradigms of decision-based design (DBD) in engineering design community (Wassenaar and Chen 2001, Hazelrigg 1998, 1999) and value-driven design in AIAA value-driven design community (Collopy and Hollingsworth 2009) are two potential alternatives for designing for value. However, in these studies the concept of value is focused to profit or surplus value, and a lot of attention is paid on the design optimization itself.

This paper focuses on the former aspect to clarify what customer values. Its intention is to provide a prescriptive approach to support value-based requirements engineering (RE). The prescriptive approach is different from normative and descriptive approaches. It helps customers or engineers to think systematically about customer needs and value by using normative theory with careful awareness of the typical ways they use in problem solving. While we certainly would like to develop a practical approach to support value-based RE, with certain consideration given to the complexity of problems and human cognitive capabilities, we want the approach to have a basis of theoretical accuracy to enhance the soundness of the approach. Our approach is based on a set of methods and theory: means-ends analysis, part-whole analysis, and multi-attribute utility theory. They are integrated together to resolve different concerns stemming from understanding customer value. Technically, this approach enables identifying implicit value, structuring logically collected customer statements, and performing value modelling and simulation from customer requirements to design parameters and vice versa. Additionally, it helps to establish the derivation from the proposed approach to traditional customer satisfaction measurement, by providing different kinds of functional forms for measuring customer satisfaction levels.

This paper is organized as follows. In Section 2, the approaches for RE in product development context are analysed with a special attention on the value concerns, e.g. implicit

customer value to reduce the possible confusion in expression, resulting from different kinds of stakeholders. However, the introduced approach is applicable to other stakeholders. 
value, weighting methods and conjoint measurement of value. In Section 3, a brief introduction about the context of approach development is given. In Section 4, the foundations underlying our approach are introduced, including the concept of "objective" and the reasons why some special methods and theories are introduced. In Section 5, our approach is proposed with its step-by-step procedures. In Section 6, we report an initial application of our approach to support value-based RE of commercial aircraft. Finally, conclusions are presented in Section 7.

\section{Approaches for RE in Product Development context}

There are already sets of approaches used for understanding customer expectations and needs, for example:

(1) The processes and methods described by Pahl and Beitz (2007) and by Ulrich and Eppinger (2007), respectively, for establishing product requirements documents,

(2) The RE processes described in system engineering standards, such as EIA 632 (1998), ISO 15288 and IEEE 1220 ,

(3) KANO model for making distinction between different degrees of customer satisfaction about different kinds of customer needs (Bayus 2007),

(4) Affinity diagram and cluster algorithms for categorizing similar or relevant customer statements into categories (Pahl and Beitz 2007), and

(5) QFD for transforming customer needs into engineering characteristics (ECs) and for calculating customer satisfaction (Hauser and Clausing 1988).

However, these approaches fail to clarify sufficiently the value concerns that are crucially important during customer decision-making and design decision-making processes. There are some obvious shortcomings of these approaches, which may hinder the design optimization based on customer value:

P1. Different levels of customer statements are not structured with sound logic. There are many possible customer needs, product features and forms, engineering characteristics, goals, attributes, constraints or design parameters in the elicited customer statements. Simple inclusion of all related or similar statements in the same groups is not appropriate and introduces unnecessary complexity to quantitative modelling in later stages of the design process. Furthermore, an important opportunity to uncover implicit customer value can be overlooked and missed. This problem is common in the whole class of affinity diagram based approaches or when a certain cluster algorithm is used to cluster statements on basis of similarity. Typically, a hierarchy is produced with these methods. For example, a hierarchy of "It is easy to use" of digital camera is given in Figure 1(Bayus 2007). 


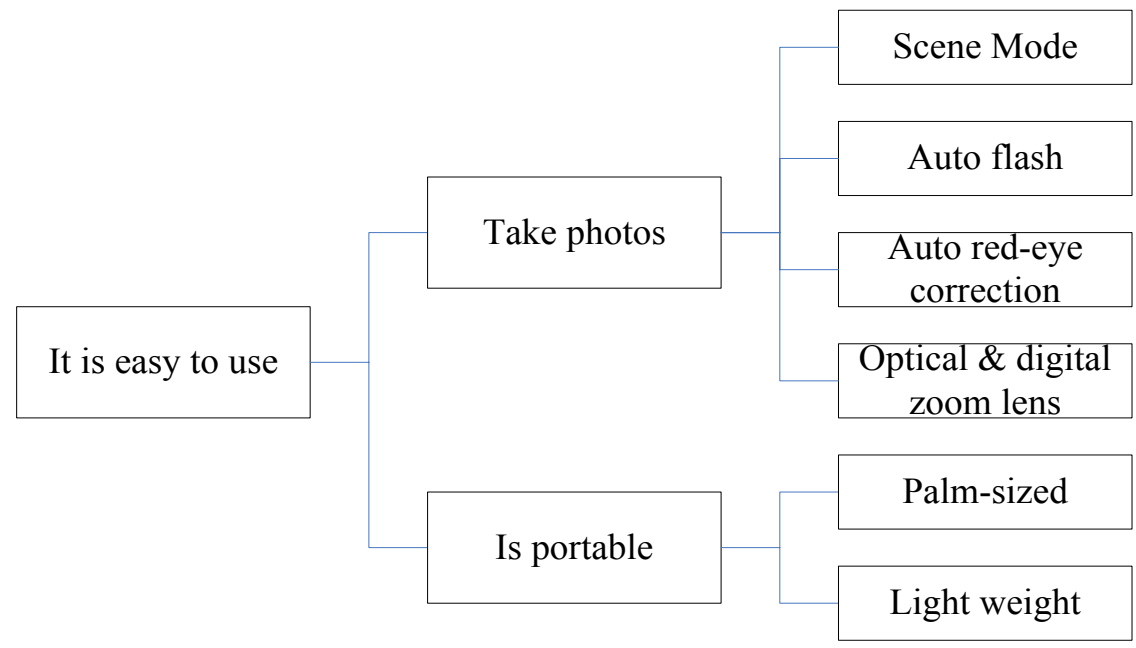

Figure 1: A customer needs hierarchy of "It is easy to use" for a digital camera.

An intuitive thinking might consider this hierarchy as a useful structure. However, in reality, it actually poses some problems. The customer needs "Take great photos" and "Is portable" are two parts of the whole "It is easy to use". These part-whole relationships are modelled in a hierarchy. However, features, such as "Scene mode" and "Auto flash", are means to influence "Take great photos" with means-ends relationships between them. Not only will "Optical and digital zoom lens" influence "Take great photos", but also influence "Light weight". It is not possible to combine these two types of relationships together in a hierarchy and these means-ends relationships would be more appropriately modelled with network. This basically hinders uncovering implicit customer needs and poses difficulty to verify independence conditions of preferences.

P2. Customer needs are almost always given weights independent from range information of attributes that is utilized for measuring the attainment of customer needs (Zhang et al. 2011). This may be caused by the ambiguity of customer needs themselves or the difficulty in identifying the measurements or metrics to be used for customer needs. However, if the weights or rankings are given without considering their range information from lowest acceptable level to highest desired level, it will be error-prone and there might be significant errors in the underlying model (Keeney 2002). This point can be easily illustrated with an example of purchasing a car. Let's assume that customers only consider the following two objectives when they decide: minimize buying cost and maximize safety. According to classic utility theory, it makes little sense to say that for example, "minimize cost" is more important than "maximize safety", or vice versa. It all depends on how much you consider cost and safety, respectively, and on where you start. It is only meaningful to say that cost is more important than safety when the range of change in cost from some starting level is more important than the range of change in safety from certain starting level. This problem is common in typical weighting processes such as the QFD method.

P3. There is a deep-rooted inclination in practice to confuse the ordinal rankings with cardinal weightings. Ranking expressed in the form of integers, such as $1,2,3,4,5$, is not allowed for 
arithmetical operations (De Poel 2007). Furthermore, it is not possible to transform a set of individual rankings given by different customers or stakeholders into a group ranking. The reason is that it will violate a set of reasonable assumptions defined by Arrow, which is well known as Arrow's Impossibility Theorem (AIM) (Keeney and Raiffa 1993, Keeney 2009). This result can be illustrated using a simply example with three customers and three customer needs that are presented in Table 1 . While $66 \%$ of customers ( $A$ and $B$ ) think that acquisition cost is more important than safety, and $66 \%$ of customers ( $A$ and $C$ ) think that safety is more important than environment impact, it is expected that the group ( $A, B$ and $C$ ) will rank acquisition cost as more important than environment impact according to "transitive" principle of rational decision-making. However, $66 \%$ of customers ( $\mathrm{B}$ and $\mathrm{C}$ ) give a higher ranking to environment impact than that of acquisition cost. This demonstrates the impossibility of deriving group rankings from individual rankings of customer needs.

Table 1: Implications of AIM in deriving group ranking of customer needs.

\begin{tabular}{|l|l|l|l|}
\hline Customer & $\begin{array}{l}\text { Acquisition } \\
\text { cost }\end{array}$ & Safety & $\begin{array}{l}\text { Environment } \\
\text { impact }\end{array}$ \\
\hline A & 1 & 2 & 3 \\
\hline B & 2 & 3 & 1 \\
\hline C & 3 & 1 & 2 \\
\hline
\end{tabular}

On the other hand, as ranking and weights are two different kinds of preferences, it is possible to do arithmetical operations on cardinal weights, and it is also possible to transform individual weights into group weights as proved by Keeney $(1975,2009)$. This confusion between rankings and weightings leads to a misconceived limitation of the QFD method.

P4. Additive linear form is usually used to measure the achievement of customer satisfaction levels, such as in the QFD method, which is a variant of cost-benefit analysis (CBA). In fact, usually the composite measurement method (sometimes called merit or goodness) is not apparent. Additionally, the following two implicit assumptions are normally made:

- An additive function form is used to aggregate different attributes. This implies that certain preference independences among attributes are satisfied, which in fact should be subjected to a rigorous verification process. In practice, a set of measurements is usually used as a basis of conjoint measurement, but sometimes they are not at the same level and fail to satisfy certain conditions of preference independence. If they are used directly in QFD or CBA, this may result in double counting and, consequently, in an arbitrary decision.

- Linear function forms are assumed regarding to the relationships between merit (or goodness) and the achievement of each attribute, that is, every unit of attribute has the same merit. But, it is again only reasonable in certain situations. Counter examples can be found in KANO model and marginal rate of substitution in economics.

The form is also suffering from an inability to cope with uncertainties in objective achievement and corresponding risk attitudes in an operationally reasonable manner. 
However, it is necessary to incorporate this consideration in value assessment for rational design decisions, because there are always uncertainties in the design, and this is especially true about the economic parameters that are not under the control of designers.

\section{Context of Development of Approach}

This development of approach to support value-focused RE builds on a current research conducted within the European Commission's Seventh Framework Programme (FP7) research project CRESCENDO in the domain of European aerospace industry in collaboration with mainly European universities and manufacturers. The test case of requirements establishment and value generation provides a beneficial link to main manufacturers (i.e., aircraft, engine, subsystems and others) in European aerospace industry and a useful input during the development of the approach. A schematic illustration of value-driven design among different levels of aerospace product is shown in Figure 2 (Cheung et al. 2012). System value model is normally used in the process to enable design evaluation and optimization in terms of value along with other physical performance attributes, such as range, thrust, specific fuel consumption, etc. and economic attributes, such as manufacturing cost, operating cost, maintenance cost, etc. The focus in this paper is on how to build a customer value model from airliners needs, expectations and other statements paralleling with traditional RE process and on how to derive customer value model into system value model.

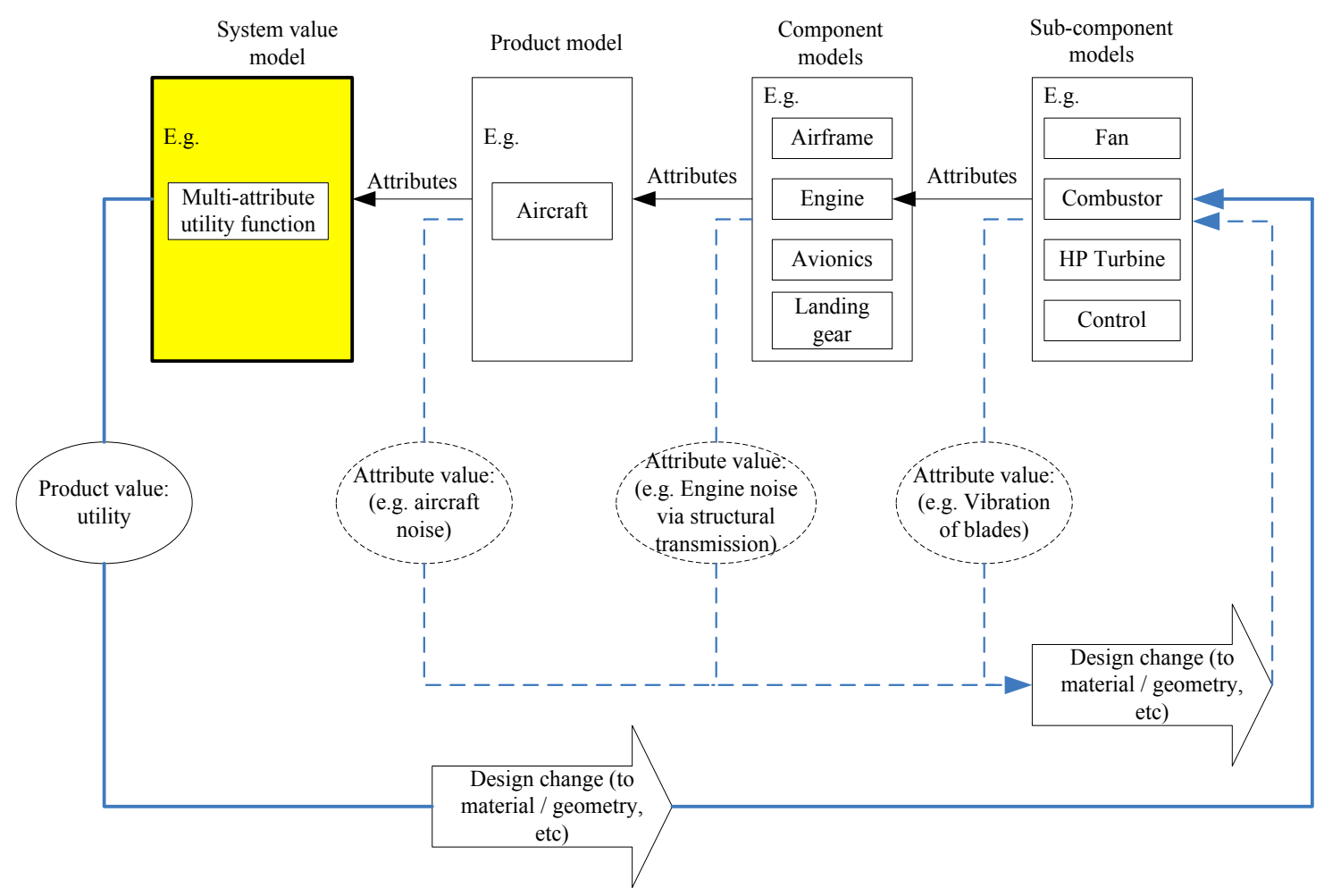

Figure 2: A schematic illustration of value-driven design in context of CRESCENDO. 
Some expectations on the value model from the aircraft manufacturer regarding the approach development and its application are the following:

E1. Establish value-driven traceability from customer expectations to requirements.

E2. Enable value-driven trade-off capability at requirements level and design solution level.

E3. Pay more attention on intangible value dimensions rather than only on a particular cost aspect (e.g. surplus value).

It is then useful to introduce techniques that can resolve or at least alleviate aforementioned problems in Section 2 and expectations from aircraft manufacturers. A prescriptive approach is introduced here as a potential solution.

It is also well recognized that a commercial aircraft is a class of very complex products. Its development demands the application of systematic processes, such as the system engineering processes in general and RE processes for establishing requirements specifications (De chazelles et al. 2004). As our intention is to focus on value at RE stage and not to depart from available best practices, a parallel process is used. One process is to develop value models through the application of the proposed approach while a traditional parallel process is employed to establish traditional requirements specification through application of available best practices.

\section{Foundations of the Approach}

From the above analysis of methodological problems in the listed approaches and collection of industrial expectations, a set of concepts, theory and methods is introduced. A corresponding relationship between them is presented in Table 2.

Table 2: Concepts and methods corresponding to expectations and problems.

\begin{tabular}{|l|l|l|}
\hline Expectations and Problems & Tools: Concepts & Tools: Methods and theory \\
\hline P1, E1 and E3 & Objectives & $\begin{array}{l}\text { Means-ends analysis, } \\
\text { Part-whole analysis }\end{array}$ \\
\hline P2, P3, P4, E2 and E3 & $\begin{array}{l}\text { Value model and } \\
\text { consequence model }\end{array}$ & Multi-attribute utility theory \\
\hline
\end{tabular}

\subsection{Objectives}

Value is made explicit through objectives (Keeney 1992). Objectives are statements of something that one desires to achieve. They are expressed in a verb and a noun format. For example, two objectives for evaluating aircrafts when customers make their decisions are: maximize quality and minimize cost. It is straightforward to transform customer statements into objectives, which share common expressions. In order to measure objectives, attributes are identified and selected.

Three kinds of objectives are needed to organize sufficiently different types of objectives: 
fundamental objectives, means objectives and strategic objectives (Keeney 1992). The determination of these three objectives depends on the selected context. Therefore, it is important to determine the current context of decision-making. It is the fundamental objectives that are the essential reasons of interest for customers. And, it is much easier for customers to perceive the value about fundamental objectives. Comparatively, customers need at least two steps to perceive appropriate value of means objectives (Keeney 1992). The abstraction underlying these three kinds of objectives is means-ends relationships. Fundamental objectives indicate what to do, means objectives indicate how to do and strategic objectives indicate why to do. Introduction of these three kinds of objectives corresponds to and explains well the value concept (Woodruff 1997) that also include three types of customer value (attributes, consequences and purposes) with means-ends relationships. Furthermore, the concept of objective and its three types enable more formal analysis to be introduced as discussed below.

\subsection{Means-ends analysis}

The essence underlying the means-ends relationships is the ability to ask "why" and "how" questions. Pursuing "why" questions leads to discover the reasons (ends) behind certain objectives and finally the fundamental reason of interest. Asking "how" questions helps to discover the possible means to influence the achievement of current objective. After this kind of a reasoning process, means objectives and fundamental objectives can be rationally and logically organized into a means-ends objectives network.

\subsection{Part-whole analysis}

There is another abstraction layer that is commonly used in complex problem solving, that is part-whole relationships. One kind of the part-whole relationships is parallel decomposition. It decomposes the whole unit in its current level into logical components in a lower level. These components should be mutually exclusive and collectively exhaustive. It is possible to perform part-whole analysis by asking such questions as "What do you mean about maximizing quality?" or "Minimizing the mass of the car body is part of which objective?" The clarification of these questions will naturally result in a hierarchy. This kind of a hierarchy (or tree) is a suitable way to clarify and organize fundamental objectives.

\subsection{Multi-attribute utility theory}

Multi-attribute utility theory is a systematic approach for composing a set of usually conflicting objectives with different incommensurable units into one common unit, which is called the utility. It helps customers to think hard about various value trade-offs and about the risk attributes towards uncertainty in achieving these objectives (Keeney 1993). Multi-attribute utility function is the result of performing utility assessment. With the use of a properly constructed utility function, it is then possible to calculate the utility of different design alternatives, and to perform sensitivity analysis based on changes of weights and attribute 
values.

The introduction of multi-attribute utility theory aims to mitigate the aforementioned concerns of problems 2, 3 and 4 in Section 2. Attributes of fundamental objectives are identified to enable meaningful value trade-offs and assign appropriate weights for the P2. Single attribute utility functions incorporate risk attitudes towards uncertainty by employing a nonlinear function form along with linear ones. There are several available utility functions for aggregating the set of attributes, e.g. an additive function is a special case of other forms, such as multiplicative utility function. For P3, group utility function is introduced rather than ranking. When there is no uncertainty involved, measurable value function is used in place of multiattribute utility function (Keeney and von Winterfeldt 2007). As analogous results hold, this paper focuses on uncertain cases and utility functions.

\subsection{Value model and consequence model}

In decision analysis, two kinds of models are discussed: consequence models and value models (Keeney and von Winterfeldt 2007). Consequence models incorporate the facts, judgments, and uncertainties inherent in decision problems to describe possible consequences of alternatives, which are found based on observations and inferences on data collected from engineering experience or experiments. A typical consequence model is a performance model of an aircraft. Value models are different, which incorporate value trade-offs and risk tolerances of decision maker to evaluate consequences. The data necessary for constructing value model is collected from the minds of decision makers. The output of value model is usually a scalar number. In the paper, the value model is in the form of multi-attribute utility function.

\section{The Approach}

In this section, the prescriptive approach is proposed to develop value models. A threestep procedure of the approach is presented in Figure 3, which connects the process with identified foundations, transforming initial customer statements into a customers' group value model and a system value model. The customers' group value model and system value model are then used to assist traditional requirements specification for value-driven design. The threestep procedure of the approach is the following: (1) Identify and structure objectives, (2) Specify attributes and construct value model, and (3) Transform fundamental objectives into ECs. 


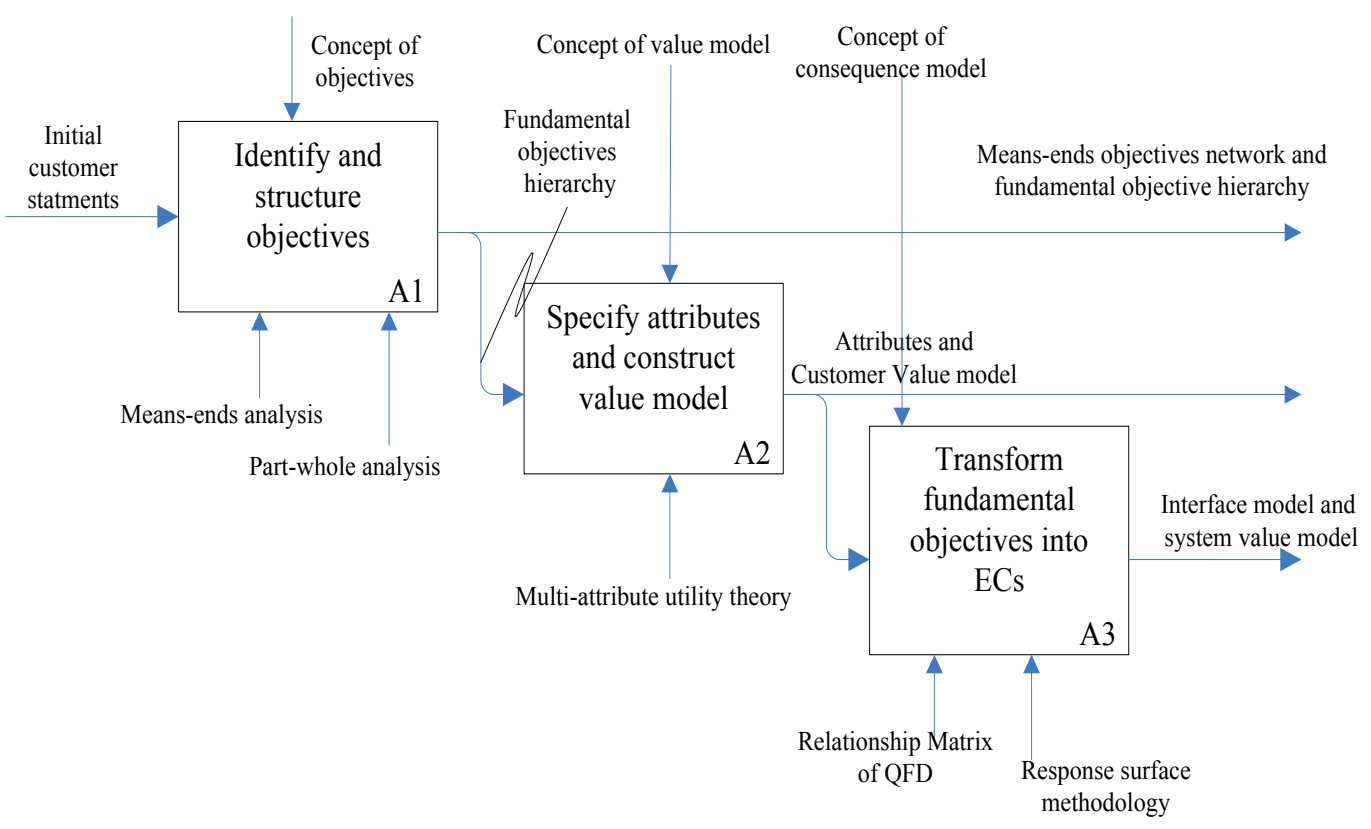

Figure 3: A three-step procedure of the approach.

\subsection{Identify and structure objectives}

The process of identifying and structuring objectives is given in Figure 4. It begins with initial customer statements and ends with establishing a hierarchy of fundamental objectives.

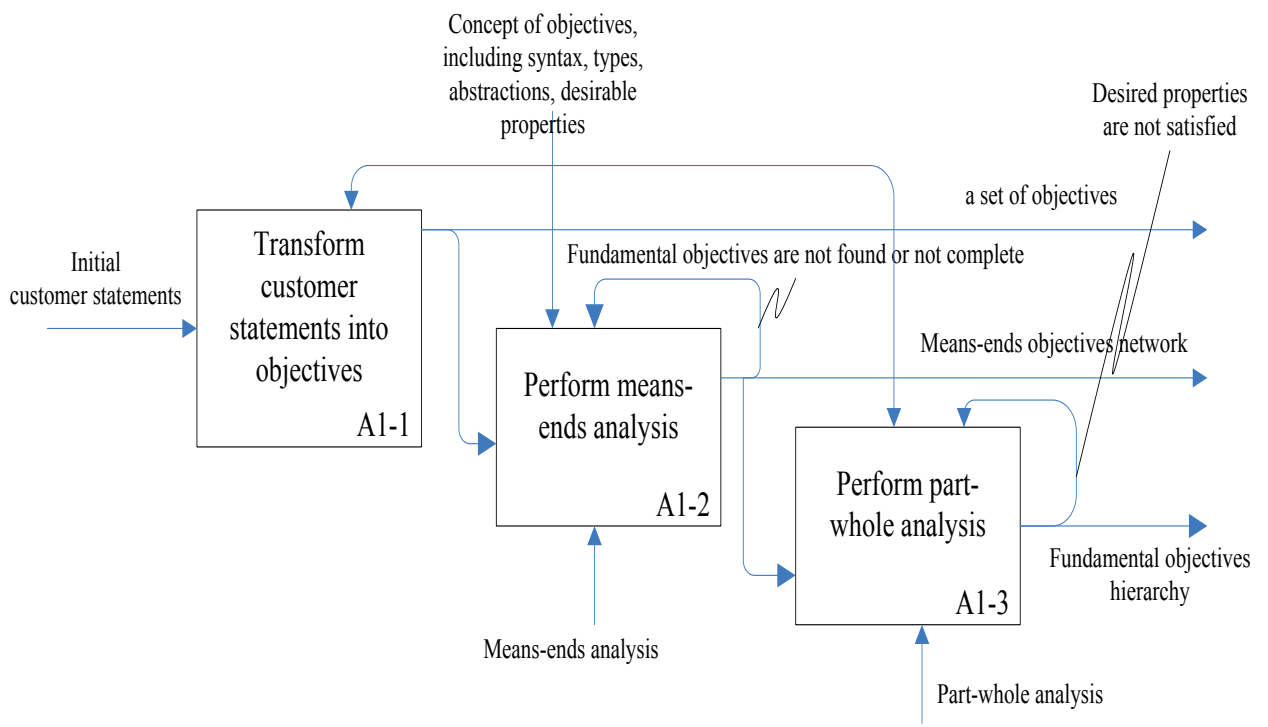

Figure 4: The process of identifying and structuring objectives. 
An obvious fact in the process is that customers try to express statements in different levels and granularities with a combination of mean-ends relationships and part-whole relationships. Usually these statements are in different expressions that hinder deep understanding of customer value. Before structuring, initial customer statements are transformed into objectives with a common expression. Means-ends analysis is then performed on these transformed objectives in different levels to discover fundamental objectives. When all the fundamental objectives in the current context are found that are in the same level, partwhole analysis is performed to identify part-whole relationships of fundamental objectives. After these activities, a hierarchy of fundamental objectives is established, which provides a well-structured form of input for the quantification process. This step will solve the methodological problem of P1.

\subsection{Specify attributes and construct value model}

The procedures of the second step are given in Figure 5. Multi-attribute utility theory is used to support this step. In order to enable transformation from qualification to quantification, certain attributes or metrics are needed to measure the achievement of each of the

fundamental objectives in the leaves of the hierarchy. Attributes are necessary to assign meaningful weights to fundamental objectives and will help to solve methodological problem of

P2. The set of identified attributes $X$ is then used as the input to construct the value model. 


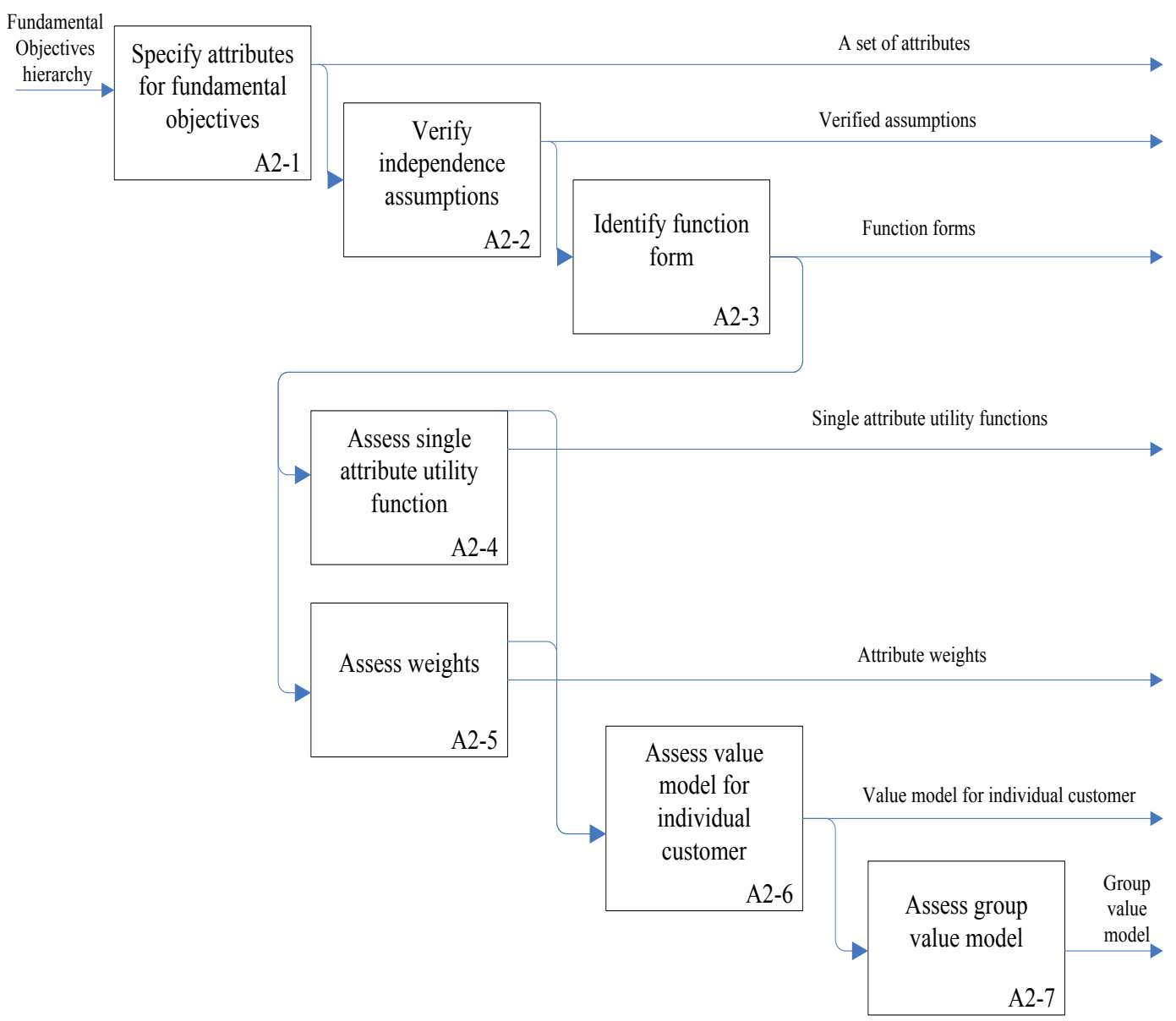

Figure 5: The process of specifying attributes and constructing value model.

Independence assumptions such as additive independence among those attributes are verified to identify a function form to compose the attributes together. If mutual preference independence among the set of attributes and utility independence of $X_{i}$ regarding to the other attributes are finally verified, the value model is of multiplicative form. If additive independence among the attributes is verified, then the value model is of a special form of multiplicative form, i.e. additive form.

There are inclinations in practice to utilize additive linear form directly without checking the preference independence conditions among attributes and without verifying the function form of single attribute utility function, which is common in QFD-based approaches (Hauser and Clausing 1988, Bode and Fung 1998). Figure 6 shows the derivation among different kinds of function forms. The implication is that the underlying preference independence conditions should be carefully realized when certain function form is finally selected, which provides solution to solve methodological problem of P4. 


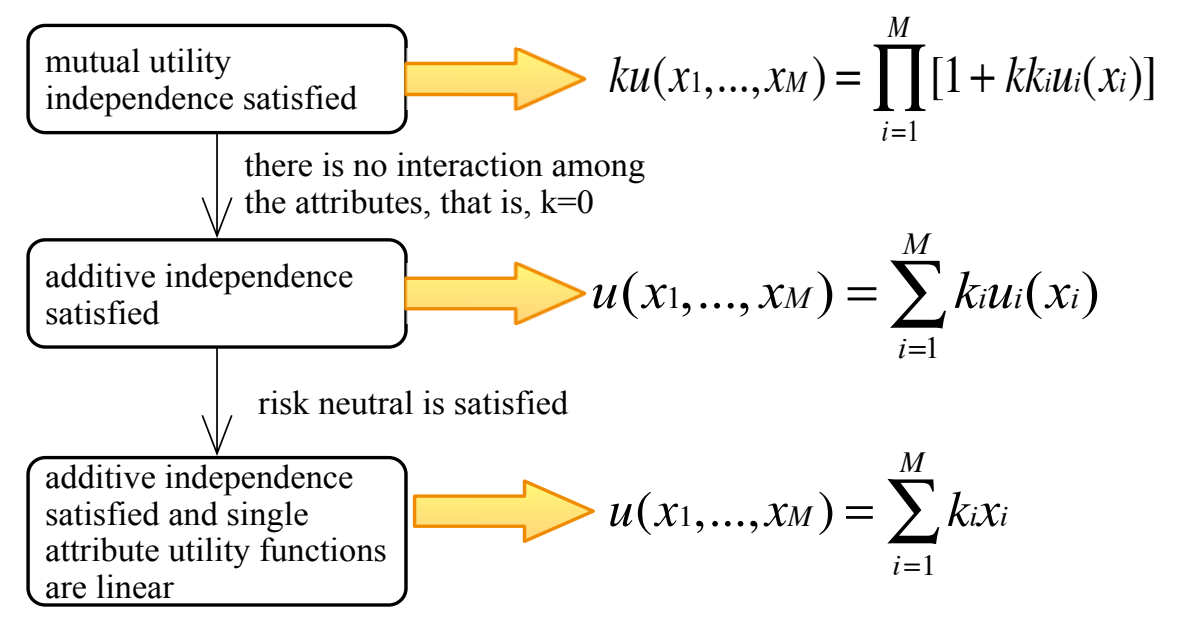

Figure 6: The derivation among different kinds of function forms.

Empirically, Keeney shows that it is appropriate to determine an additive function form when the set of objectives are fundamental objectives and the objectives satisfy the set of desired properties of fundamental objectives (Keeney 1992). After carefully performing meansends and part-whole analysis, we have confidence that additive function form

$$
u\left(x_{1}, \ldots, x_{M}\right)=\sum_{i=1}^{M} k_{i} u_{i}\left(x_{i}\right)
$$

is a reasonable approximation of customer preferences.

Single attribute utility functions for attributes are then assessed. Necessary information for assessing one single attribute utility function includes: (1) range information of the attribute, (2) the monotonicity of the utility function, (3) risk attitude of the customer towards the uncertainty attainment of the attribute, and (4) certainty equivalence (or lottery equivalence).

Scale constants (or weights) $k_{i}^{\prime}$ s are assessed through making value trade-offs. Value trade-off defines how much must be improved in the attainment of one attribute to compensate for a lesser attainment in another attribute. They are usually performed using pairs of two possible hypothetical alternatives with the same utilities to customers but differ only in levels of achievement of two attributes. Two indifferent consequences are modelled through:

$$
u\left(x_{1}, \ldots, x_{i}, \ldots, x_{j}, \ldots, x_{M}\right)=u\left(x_{1}, \ldots, x_{i}^{*}, \ldots, x_{j}^{*}, \ldots, x_{M}\right)
$$

For $M$ attributes, a set of at least $M$ equations has to be constructed to determine the $M$ $k_{i}^{\prime}$ 's in the additive function form. Sometimes iterations may be necessary when the equations are not independent from each other. After assessing the $k_{i}^{\prime} s$, the value model of an individual customer is finally constructed by combining identified function form, assessed single attribute utility functions and weights.

However, different customers may have different preferences about attributes and their 
importance. In most applications of the QFD method, an assumption is made that customers could finally achieve a compromise and reach consensus about the importance of customer needs. However, if consensus cannot be achieved, group preferences always have to be modelled. Customers then may have different value models, even if the same set of fundamental objectives and attributes is used for assessment. Some attributes may be assigned a higher weight by a certain customer while others may assign them a lower weight. Customers may even have different perceptions about single attribute achievement.

Hazelrigg (1999) and others (Franssen 2005) show the impossibility of deriving group preferences according to Arrow's Impossibility Theorem (AIT). But ranking and weights are two different types of preference as discussed by Keeney (2009):

"Arrow's Impossibility Theorem, has been misinterpreted by many (e.g., Hazelrigg, 1999; Franssen, 2005). ...... But Arrow's result is more specific: it is for a specific type of preference, namely rankings, and a specific set of assumptions, namely the assumptions that he chose."

One can derive group utilities for group decisions by aggregating the utilities of different airlines, proved by Harsanyi (1955), Sen (1970), and Keeney (2009). That is, it is possible to derive a group utility from a set of $N$ individual utilities when interpersonal comparison and strength of preference information are addressed. Thus, assessing group utility function can solve the methodological problem of P3.

A group value model for $N$ customers with $M$ attributes is:

$$
u_{G}=\sum_{s=1}^{N} w_{s} u^{(s)}(x), i=1, \ldots, M
$$

If there are a large number of customers, it takes time to assess value models for each customer. It is then more reasonable to aggregate or categorize customers into several types with the help of other methods and tools. If uncertain achievement of attributes is important, group expected utility could also be derived.

\subsection{Transform fundamental objectives into ECs}

Fundamental objectives should be transformed into ECs that have the means to influence the achievement of fundamental objectives. The procedures of the third step are presented in Figure 7. 


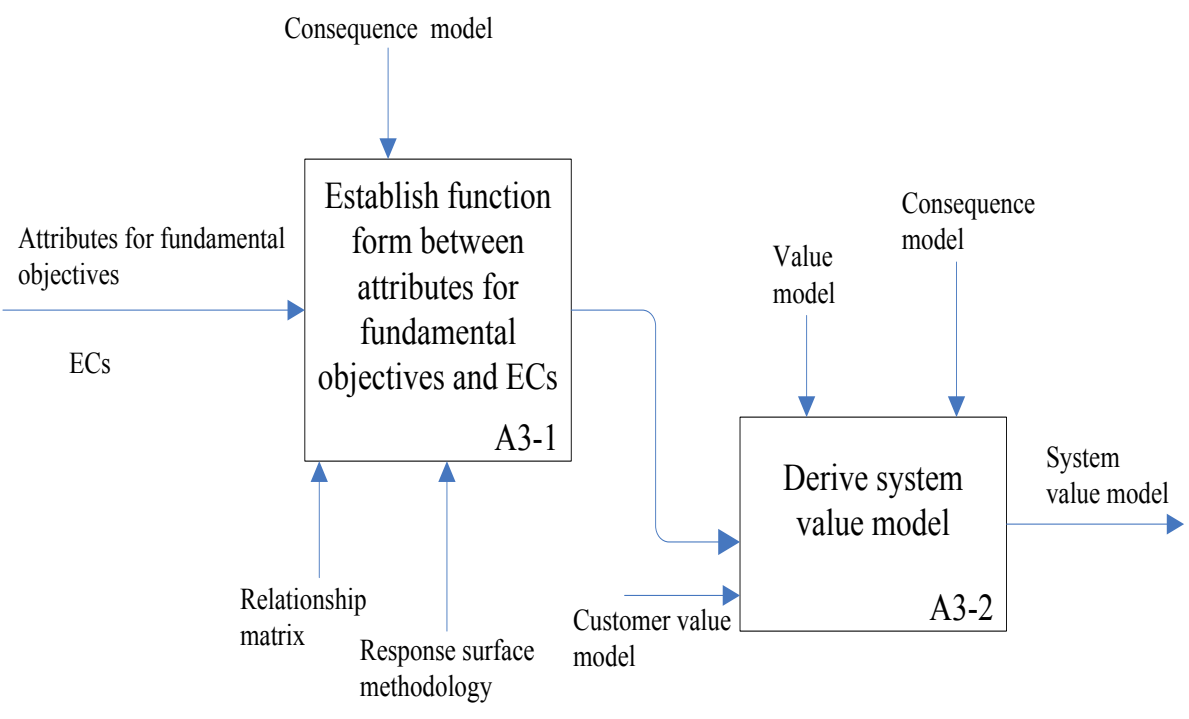

Figure 7: The process of transforming fundamental objectives into ECs

The relationships between attributes for fundamental objectives and ECs are firstly expressed in two levels of a means-ends objectives network. This network is modelled in the house of quality with a two-dimensional matrix. The relationship matrix is usually filled with, for example, 1-3-9 scales. These scales provide a convenient way to measure the influence relationships, but they are not precise. There are other approximations, such as the response surface equations. They are simplification of this function form:

$$
x_{i}=f_{i}\left(y_{1}, \ldots, y_{Q}\right), i=1, \ldots, M
$$

It is then possible to calculate the utility of a design alternative with a vector of $Y$ by combining customer value model with the function form (4):

$$
u_{Y}\left(y_{1}, \ldots, y_{Q}\right)=u\left(x_{1}, \ldots, x_{M}\right)=\sum_{i=1}^{M} k_{i} u_{i}\left(f_{i}\left(y_{1}, \ldots, y_{Q}\right)\right)
$$

Equation (5) is a system values model that models the utility of ECs of the system. The underlying fact in this equation is that it is a two-step modelling process, as presented in Figure 7. In the first step, the consequence model from ECs to attributes for fundamental objectives is modelled by considering means-ends relationships. It is then combined with the customer value model to derive a system value model that reflects the influence of ECs on system value. It is different from the one-step process that models directly the relationships from ECs to value without identifying the implicit fundamental objectives (Scanlan et al. 2011).

\section{The Application}

In this Section, the proposed approach is applied to assist requirements engineering of commercial aircraft development. For the aircraft design and manufacturing process, it is intuitively attractive for the manufacturer to transform airlines' fundamental objectives to toplevel aircraft requirements, such as range, payload, maximum take-off weight, and take-off field length, and use these relationships for design optimization. However, these transformation relationships have not be established and typically, cost or weight based optimization is used in 
current aircraft design practice. More fundamental research is needed to model their qualitative relationships and functional forms, which is outside of the scope of this paper. Because of this limitation, the application case focuses on the first two-steps of the approach, and airlines' group value model is constructed in this process.

\section{Step 1: Identify and structure objectives}

The initial airlines' statements in the Table 3 are used as the starting point for deriving value model. Although they are incomplete, they are sufficient for the illustration of the approach.

The types and examples of initial airline statements are partly given in the first two columns of Table 3. An obvious fact regarding to the statements is that airlines try to express statements in different levels and granularities. The airline statements may be in the form of needs, goals, objectives, constraints, ECs, or design parameters. It is straightforward to transform the initial statements into objectives as shown in the third column of Table 3. However, these transformations do not eliminate those original customer statements that are also useful for design. For example, the imposed constraints are usually to be utilized to check the technical feasibility and economic viability of various design alternatives.

These transformed objectives may be fundamental, means or strategic objectives. The objective of "minimize operating cost" is a fundamental objective for chosen airlines, as they think it is one of the fundamental reasons to select a commercial aircraft. It is possible to ask why "minimize operating cost is important", and the answer may be that it directly influences profit levels. On the other hand, profit is also influenced by other means, such as pricing, marketing and strategy, which are not under the control of the current decision context of aircraft development.

"Minimize fuel consumption" is a means objective, although there is a high frequency of requests by airlines. The underlying reasons are that it influences positively the achievement of "minimize operating cost" and "minimize environment impact", which are fundamental objectives. "Provide commonality" is also a means objective, which influence positively "minimize operating cost" and "maximize maintainability", and it may influence "maximize performance" negatively, such as the range and the maximum take-off weight of the aircraft. Through means-ends analysis on "provide commonality", it is found that it is difficult to make sensible decisions when commonality is considered directly. The decisions of how much commonality to realize should all depend on its influence on operating cost, maintainability and usability. Then value trade-offs should be made among operating cost, maintainability and usability to determine the degree of commonality. A reckless combination of commonality, operating cost, maintainability, performance and usability without distinguishing the underlying means-ends relationships will result in double counting the importance of commonality. This simply highlights the importance of identifying fundamental objectives.

Table 3: Part of initial customer statements, their transformed objectives.

\begin{tabular}{|l|l|l|l|}
\hline $\begin{array}{l}\text { Types ox } \\
\text { statements }\end{array}$ & Examples & Transformed objectives & $\begin{array}{l}\text { Types of } \\
\text { objectives }\end{array}$ \\
\hline $\begin{array}{l}\text { Customer } \\
\text { need }\end{array}$ & Minimize operating cost & Minimize operating cost & Fundamental \\
\hline
\end{tabular}




\begin{tabular}{|l|l|l|l|}
\hline $\begin{array}{l}\text { Customer } \\
\text { need }\end{array}$ & Reduce environmental impact & $\begin{array}{l}\text { Minimize environmental } \\
\text { impact }\end{array}$ & Fundamental \\
\hline Others & Minimize fuel consumption & Minimize fuel consumption & Means \\
\hline Others & $\begin{array}{l}\text { Standardization and commonality } \\
\text { is desired }\end{array}$ & $\begin{array}{l}\text { Provide standardization } \\
\text { and commonality }\end{array}$ & Means \\
\hline Goal & $\begin{array}{l}\text { Range is expected to achieve } \\
9000 \mathrm{~nm}\end{array}$ & Maximize range & Means \\
\hline Constraint & $\begin{array}{l}\text { Approach speed must lower than } \\
150 \mathrm{kts}\end{array}$ & Optimize approach speed & Means \\
\hline $\begin{array}{l}\text { Proposed } \\
\text { technology }\end{array}$ & $\begin{array}{l}\text { The natural laminar flow has } \\
\text { important potential to reduce } \\
\text { drag }\end{array}$ & $\begin{array}{l}\text { Utilize natural laminar flow } \\
\text { when design the wing }\end{array}$ & Means \\
\hline Others & Fleet rationalization & Rationalize fleet & Strategic \\
\hline
\end{tabular}

Transformed objectives may be strategic objectives, such as "rationalize fleet". They are at a very high level to be controlled by decisions under the aircraft development programme. "How" questions should be pursued to explore its relationship with aircraft development. The outcome may be that current fleet is in a certain situation in which longer range and more fuelefficient aircrafts are needed. This will help to find the underlying fundamental objectives.

After a complete means-ends analysis on the objectives in Table 3, a means-ends objectives network is established and a set of fundamental objectives is identified. Those uncovered fundamental objectives from the transformed objectives are presented in Table 4.

Table 4: Transformed objective and their fundamental objectives.

\begin{tabular}{|l|l|l|}
\hline Transformed objectives & $\begin{array}{l}\text { Types of } \\
\text { objectives }\end{array}$ & Uncovered fundamental objectives \\
\hline Minimize operating cost & Fundamental & \\
\hline $\begin{array}{l}\text { Minimize environmental } \\
\text { impact }\end{array}$ & Fundamental & \\
\hline $\begin{array}{l}\text { Minimize fuel } \\
\text { consumption }\end{array}$ & Means & $\begin{array}{l}\text { Minimize operating cost, minimize environment } \\
\text { impact }\end{array}$ \\
\hline $\begin{array}{l}\text { Provide standardization } \\
\text { and commonality }\end{array}$ & Means & $\begin{array}{l}\text { Minimize operating cost, maximize usability, } \\
\text { maximize maintainability }\end{array}$ \\
\hline Maximize range & Means & $\begin{array}{l}\text { Part of "Maximize performance" (means), which } \\
\text { influences operating cost, usability }\end{array}$ \\
\hline Optimize approach speed & Means & $\begin{array}{l}\text { Minimize operating cost, minimize environment } \\
\text { impact, maximize usability, maximize safety, } \\
\text { maximize reliability }\end{array}$ \\
\hline $\begin{array}{l}\text { Utilize natural laminar } \\
\text { flow when design the } \\
\text { wing }\end{array}$ & Means & $\begin{array}{l}\text { Minimize operating cost, minimize environment } \\
\text { impact, maximize usability, maximize maintainability }\end{array}$ \\
\hline Rationalize fleet & Strategic
\end{tabular}

It is then necessary to perform part-whole analysis on the fundamental objectives in Figure 8 , which helps to clarify the understanding of fundamental objectives of high levels and granularities. 


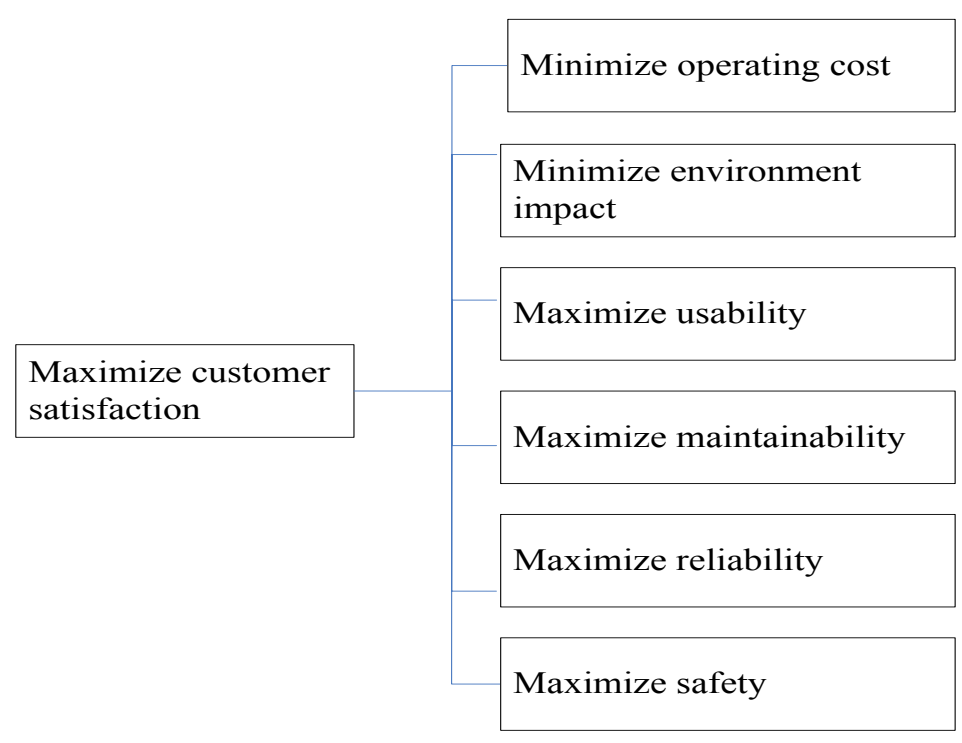

Figure 8: The fundamental objectives established from transformed objectives.

A fundamental objectives hierarchy for the objectives of "Minimize environmental impact" is given in Figure 9, which is a sub-hierarchy in Figure 8. In this figure, a narrow perspective is adopted and environmental impact is limited to noise and emission impact that will be sufficient to illustrate the process and methods. In this hierarchy, the objective of minimizing environmental impact is decomposed into a degree at which appropriate attributes for measurement can be selected. The same procedures are performed in other fundamental objectives, such as "Minimize operating cost". Finally, a complete hierarchy of all the fundamental objectives is established. 


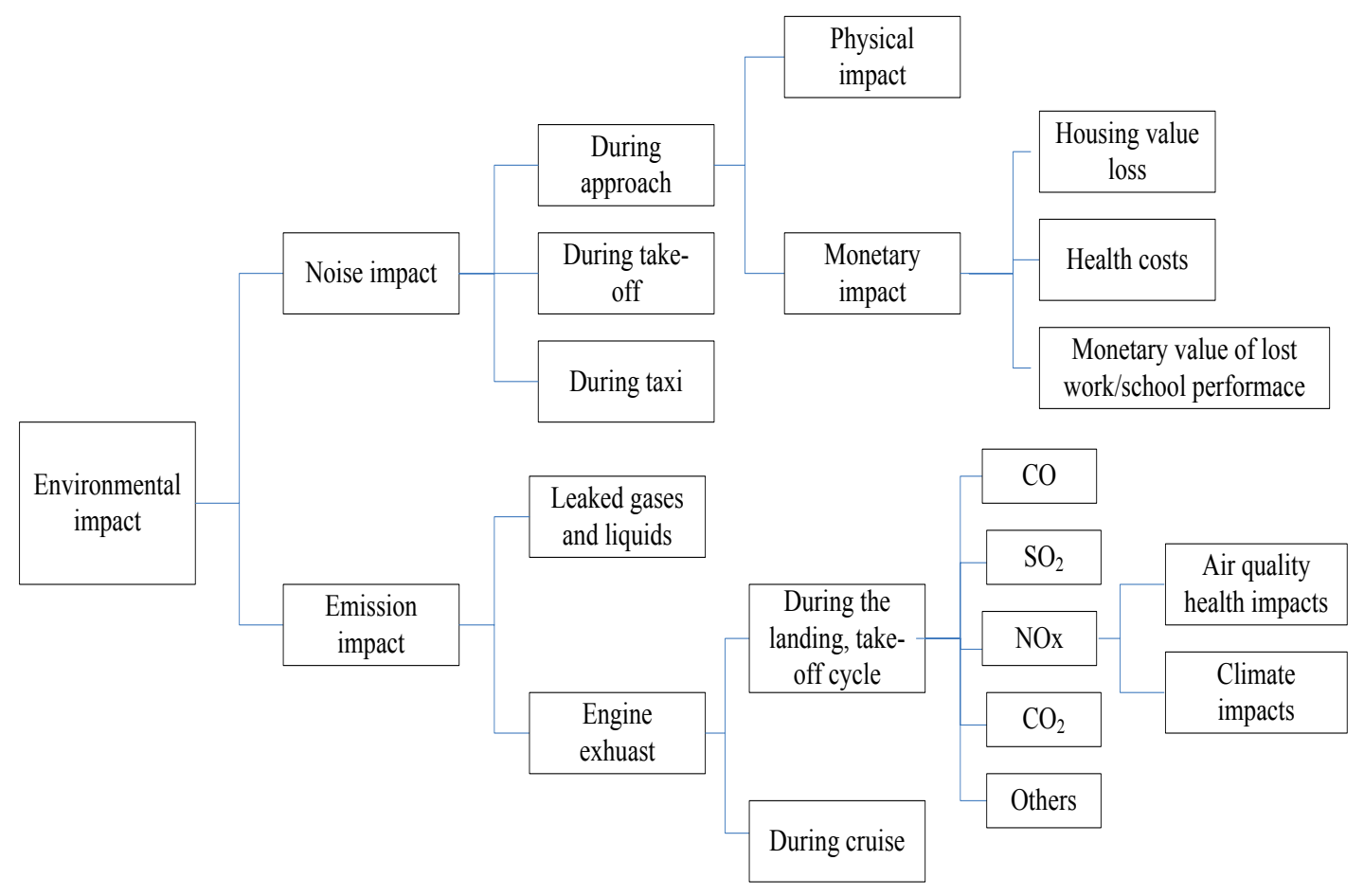

Figure 9: A hierarchy of fundamental objective of "minimizing environmental impact".

Through means-ends and part-whole analysis, hard work and creative thinking on these objectives, confidence is established that the set of fundamental objectives satisfies the desired properties of fundamental objectives specified by Keeney (1992). Thus the procedure facilitates further quantification and value measurements.

Step 2: Specify attributes and construct value model

Attributes are identified to measure the fundamental objectives in the hierarchy of airlines' fundamental objectives. Seat mile cost measured in 2011 dollars is a natural attribute regarding to operational cost. A constructed attribute with four levels is used for safety measurement in Joint Airworthiness Requirements: Minor, Major, Hazardous and Catastrophic. Every level is given clear clarification in value so that customers or designers can easily find the safety level of a special aircraft. "Mean maintenance man-hours per flight hour" is selected as an attribute for "Maximize maintainability". "Dispatch reliability rate measured in \%" is an attribute for "Maximize reliability". For usability of airplane, one attribute is identified for each function in appropriate levels and for airplane's capability to commit certain route, and these attributes are expressed as elements of a vector.

However, for some objectives, it may be too difficult to identify direct measurements or collect the information for these direct measurements. For example, the overall health cost resulting from noise impact is very difficult to collect. Proxy attributes are then used as indirect measurements for fundamental objectives, which may be the direct measurement of some means objectives. For example, attribute $X_{1}$ effective perceived noise in decibels (EPNdB) is a proxy attribute for noise impact that may be more appropriately measured by health impact 
$\left(X_{2}\right)$, noise depreciation index and monetary impact (Mahashabde et al. 2011). However, introducing of proxy attributes, e.g. EPNdB and $\mathrm{NO}_{x}$ emission, causes difficulty of verifying independence assumptions and assessing value models at later stages. For example, to assess value model of attribute $X_{1}$ in terms of "health impact $X_{2}$ ", meaningfully, a two-level process is implied. The function between $x_{1}$ and $x_{2}$ is necessary to be found firstly. Possibly, it is modelled with a conditional probability function $p\left(x_{2} / x_{1}\right)$. Then single attribute utility function over $X_{2}$ is assessed. These together give single attribute utility function over $X_{1}$.

It is desirable that the set of selected attributes satisfies desired properties of attributes, e.g. measurable, operational, direct and unambiguous. And, there are one-to-one relationships rather than multiple-to-multiple relationships between objectives and attributes. In order to facilitate the latter illustration, we assume that there is a set of $M$ objectives $\left\{O_{1}, \ldots, O_{M}\right\}$ in the leaves of the fundamental objectives hierarchy of airlines with a set of $M$ attributes $\left\{X_{1}, \ldots, X_{M}\right\}$, that is, one attribute for one objective. We also assume that the selected attributes are all direct attributes and there is a transformation process from these direct attributes to ECs that are proxy attributes for fundamental objectives. These assumptions are reasonable, although they introduce the difficulty of modelling or approximating the relationships between direct customer attributes and proxy attributes.

After specifying attributes, it is time to verify possible preference independence assumptions among attributes, which help finding function forms of the value model, e.g. multiplicative or additive function forms. After carefully performing means-ends and part-whole analysis, we have confidence that additive function form is a reasonable approximation of airline preferences.

Single attribute utility functions for attributes are then assessed. For example, one hypothetical single attribute utility function over seat-mile cost is modelled and illustrated in Figure 10, which is a decreasing risk averse utility function with concave shape. The single attribute utility function over man-hours per flight hour is assessed of risk neutrality, which has a linear form. 


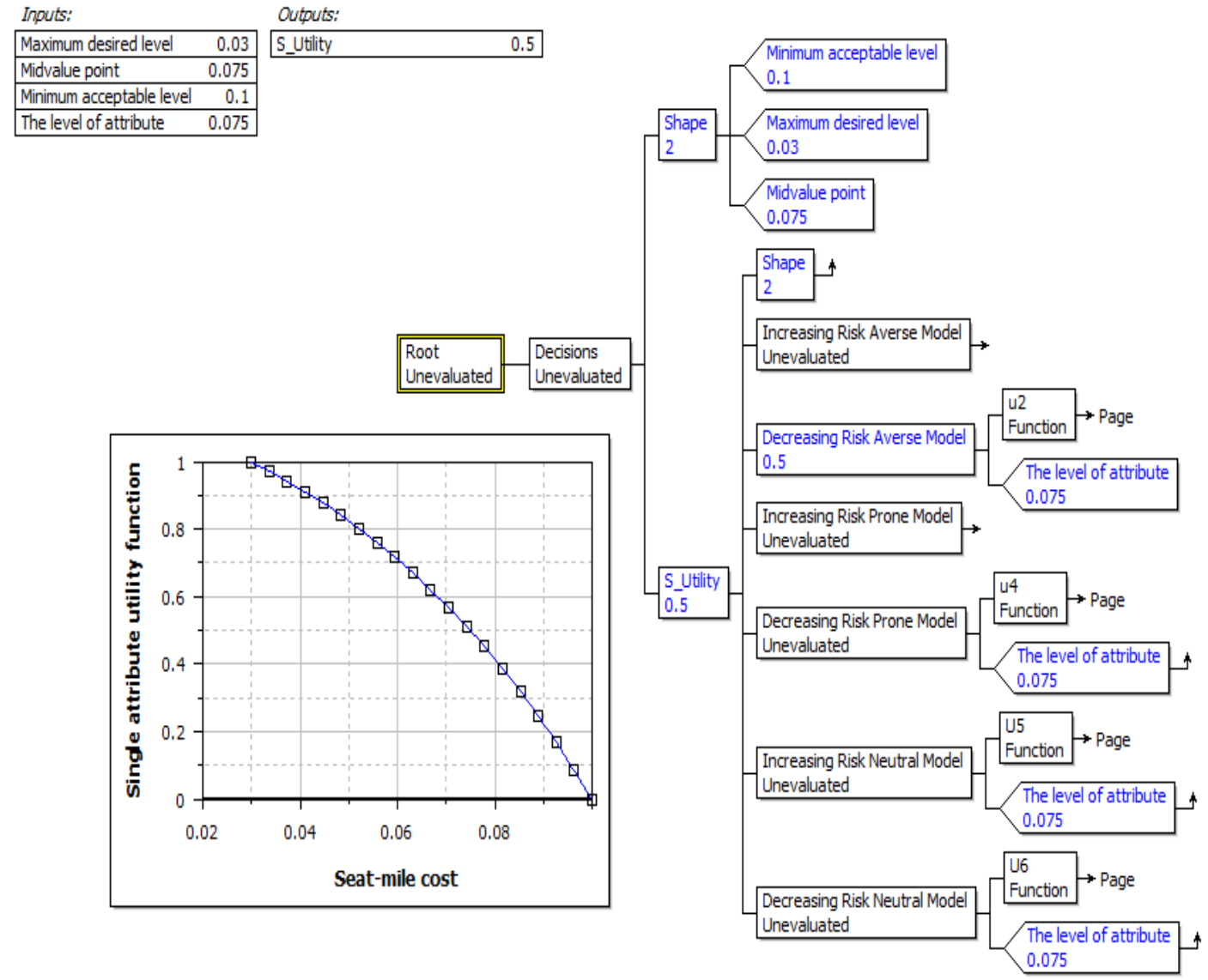

Figure 10: Single attribute utility function: seat-mile cost.

These assessments of single attribute utility functions are implemented in the Vanguard Studio modelling tool, which is one of business software for decision analysis and has a wide range of applications in industries and by our partners. A Vanguard Studio model has been developed for the assessment, which includes six possible sub-models and can be found in (Zhang et al. 2012).

Scale constants (or relative importance) $k_{i}^{\prime}$ s are then assessed. For example, with two hypothetical alternatives of the same utilities for airlines differing only in achievement of two attributes: seat-mile cost $\left(X_{i}\right)$ and man-hours maintenance per flight hour $\left(X_{j}\right)$. If an airline would like to pay 0.01 dollar more in seat-mile cost in order to exchange a reduction of 0.2 man-hours maintenance per flight hour, then

$$
u\left(x_{1}, \ldots, 0.03, \ldots, 0.3, \ldots, x_{M}\right)=u\left(x_{1}, \ldots, 0.04, \ldots, 0.1, \ldots, x_{M}\right)
$$

is satisfied, which is visually displayed in Figure 11 . Weight ratio between $k_{j}$ and $k_{i}$ is shown at the bottom of the figure, which shows one equation with $k_{i}^{\prime}$ s as unknown. 


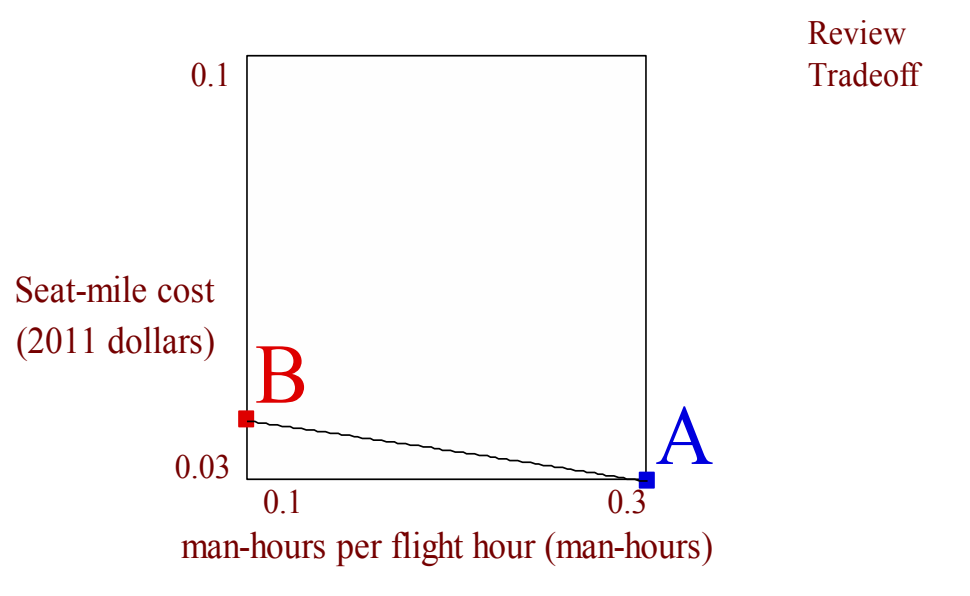

$\begin{array}{cccc} & \text { A } & \text { B } & \text { A-B } \\ \text { man-hours per flight hour (man-hours): } & 0.3 & 0.1 & 0.2 \\ \text { Seat-mile cost (2011 dollars): } & 0.03 & 0.04 & -0.01\end{array}$

man-hours per flight hour Measure Weight:Seat-mile cost Measure Weight $=0.0801682: 1$

Figure 11: Value trade-off to determine relative weights.

$M$ equations are constructed to determine the $M k_{i}^{\prime} s$ in this additive function form. These equations are linear and can be easily solved in Vanguard Studio. The roots of these equations are the $k_{i}^{\prime}$ s. After assessing function form for the multiple attributes, single attribute utility functions and $k_{i}^{\prime}$ s, a multi-attribute value model for individual airline is established.

However, different airlines have different preferences about attributes and their importance. They then have different value models, although the same set of fundamental objectives and attributes is used for assessment. Some attributes may be assigned a higher weight by a certain airline while others may assign them a lower weight. Airlines may even have different perceptions about single attribute achievement. If consensus cannot be achieved, group preferences have always to be derived.

In order to simplify the illustration, we should consider the case of two airlines. One airline is a low-cost carrier and the other is a flagship carrier. They have the same set of fundamental objectives that are narrowed down to three in our context. This example is demonstrated in Table 5. However, they have different preferences about relative weights and attainment of objectives.

Table 5: A group utility problem.

\begin{tabular}{|c|c|c|c|}
\hline \multirow{7}{*}{ Group } & Customer & Fundamental objectives & Attributes \\
\hline & \multirow{3}{*}{$\begin{array}{l}\text { Flagship } \\
\text { airline } 1\end{array}$} & Minimize operating cost & $\mathrm{X}_{1}$ : Seat-mile cost measured in 2011 dollars \\
\hline & & $\begin{array}{l}\text { Maximize } \\
\text { maintainability }\end{array}$ & $\mathrm{X}_{2}$ : Man-hours maintenance per flight hour \\
\hline & & Maximize reliability & $\mathrm{X}_{3}$ : Dispatch reliability rate measured in $\%$ \\
\hline & \multirow{3}{*}{$\begin{array}{l}\text { Low-cost } \\
\text { airline } 2\end{array}$} & Minimize operating cost & $\mathrm{X}_{1}$ : Seat-mile cost measured in 2011 dollars \\
\hline & & $\begin{array}{l}\text { Maximize } \\
\text { maintainability }\end{array}$ & $\mathrm{X}_{2}$ : Man-hours maintenance per flight hour \\
\hline & & Maximize reliability & $\mathrm{X}_{3}$ : Dispatch reliability rate measured in $\%$ \\
\hline
\end{tabular}


A formulation of the group utility problem in Table 5 is given in Table 6 . In this case, the Supra Decision Maker (Keeney 1993) is the aircraft manufacturer who verifies the assumptions and assesses the scaling constants $w_{s}$ that address interpersonal comparison of utility. In order for an aircraft manufacturer to meaningfully assign relative weights of airlines, a sophisticated assessment process is necessary, which is another decision-making problem of multiple objectives. The weights of airlines are influenced by percentage of orders, market potential, political considerations and others. The weights of the attributes and single attribute utility functions for the flagship airlines and low-cost airlines are assessed through the same procedures discussed for assessing individual customer (airline) value model. The group value model in Table 6 reveals the fact that flagship airline gives less weight to attribute of cost than low-cost airline, and that low-cost airline is more sensitive to operation cost then flagship airline. And the two airlines have different perceptions of the same achievement of operation cost as revealed in the $u_{11}\left(x_{1}\right)$ and $u_{21}\left(x_{1}\right)$.

Table 6: A formulation of group utility problem.

\begin{tabular}{|c|c|c|c|c|c|}
\hline \multirow{7}{*}{$\begin{array}{l}\text { Group } \\
\boldsymbol{u}_{G} \\
=\sum_{s=1}^{2} \boldsymbol{w}_{s} \boldsymbol{u}^{(s)}(\boldsymbol{x})\end{array}$} & Customer & $\begin{array}{l}\text { Importance } \\
\text { of customer }\end{array}$ & Attribute & $\begin{array}{l}\text { Weight of } \\
\text { attribute }\end{array}$ & Single attribute utility function \\
\hline & \multirow[t]{3}{*}{$\begin{array}{l}\text { Flagship } \\
\text { airline 1 }\end{array}$} & \multirow[t]{3}{*}{0.35} & $\overline{X_{1}}$ & 0.7531 & $\begin{array}{l}u_{11}\left(x_{1}\right) \\
=1.05184 \\
+0.01427\left(-e^{43.00272 x_{1}}\right)\end{array}$ \\
\hline & & & $X_{2}$ & 0.02098 & $u_{12}\left(x_{2}\right)=1.5-5 x_{2}$ \\
\hline & & & $\overline{X_{3}}$ & 0.22593 & $\begin{array}{l}u_{13}\left(x_{3}\right) \\
=1.30902 \\
+2.2534 e^{13}\left(-e^{-32.08079 x_{3}}\right)\end{array}$ \\
\hline & \multirow[t]{3}{*}{$\begin{array}{l}\text { Low-cost } \\
\text { airline } 2\end{array}$} & \multirow[t]{3}{*}{0.65} & $\overline{X_{I}}$ & 0.78115 & $\begin{array}{l}u_{21}\left(x_{1}\right) \\
=1.42477 \\
+0.25287\left(-e^{17.28891 x_{1}}\right)\end{array}$ \\
\hline & & & $X_{2}$ & 0.06262 & $u_{22}\left(x_{2}\right)=1.5-5 x_{2}$ \\
\hline & & & $X_{3}$ & 0.15623 & $\begin{array}{l}u_{23}\left(x_{3}\right) \\
=1.06002 \\
+2.2422 e^{36}\left(-e^{-63.80672 x_{3}}\right)\end{array}$ \\
\hline
\end{tabular}

With a quantified group value model and several individual value models, it is then possible to perform various kinds of visual analysis, sensitivity analysis and optimization. Figure 12 represents the implemented model of group utility function and a color-based sensitivity analysis, which shows the degree of relevance between customer attributes and group utility. Differences between airlines can be identified: different relative weights of airlines, different perception of attribute attainment and different relative weights of attributes. Individual utilities are assessed and aggregated meaningfully into group utility without making a compromise between airlines. 


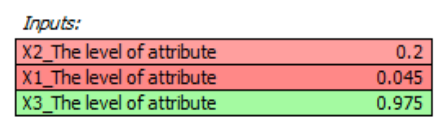

Outputs:

Customer 1 utility $\quad 0.89134$

Customer 2 utility 0.84623

Group utility

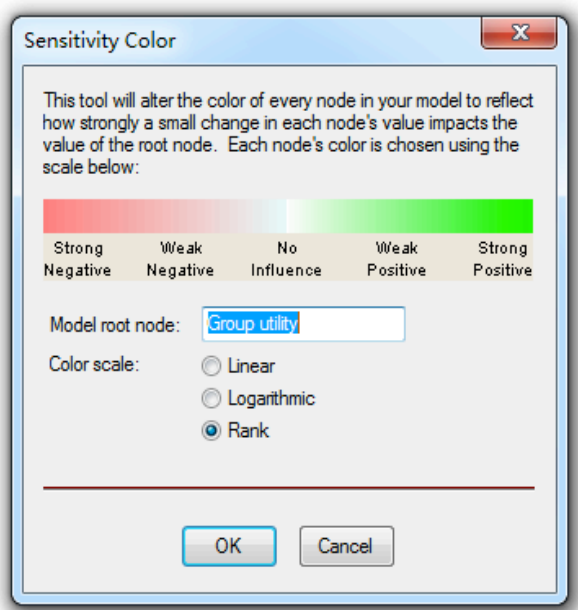

0.86202

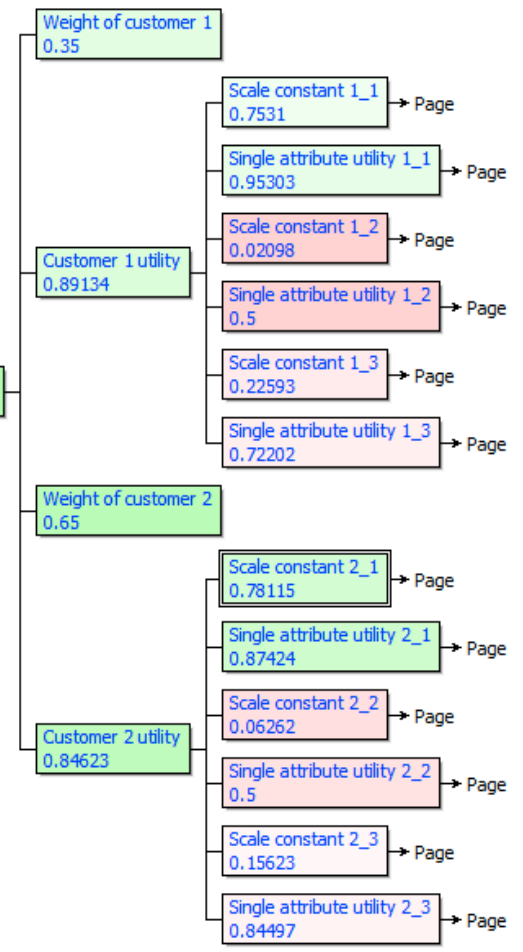

Figure 12 . Group utility and color-based sensitivity analysis

Other capabilities of value modelling and simulation are also implemented. Parts of them are shown in Figure 13. 


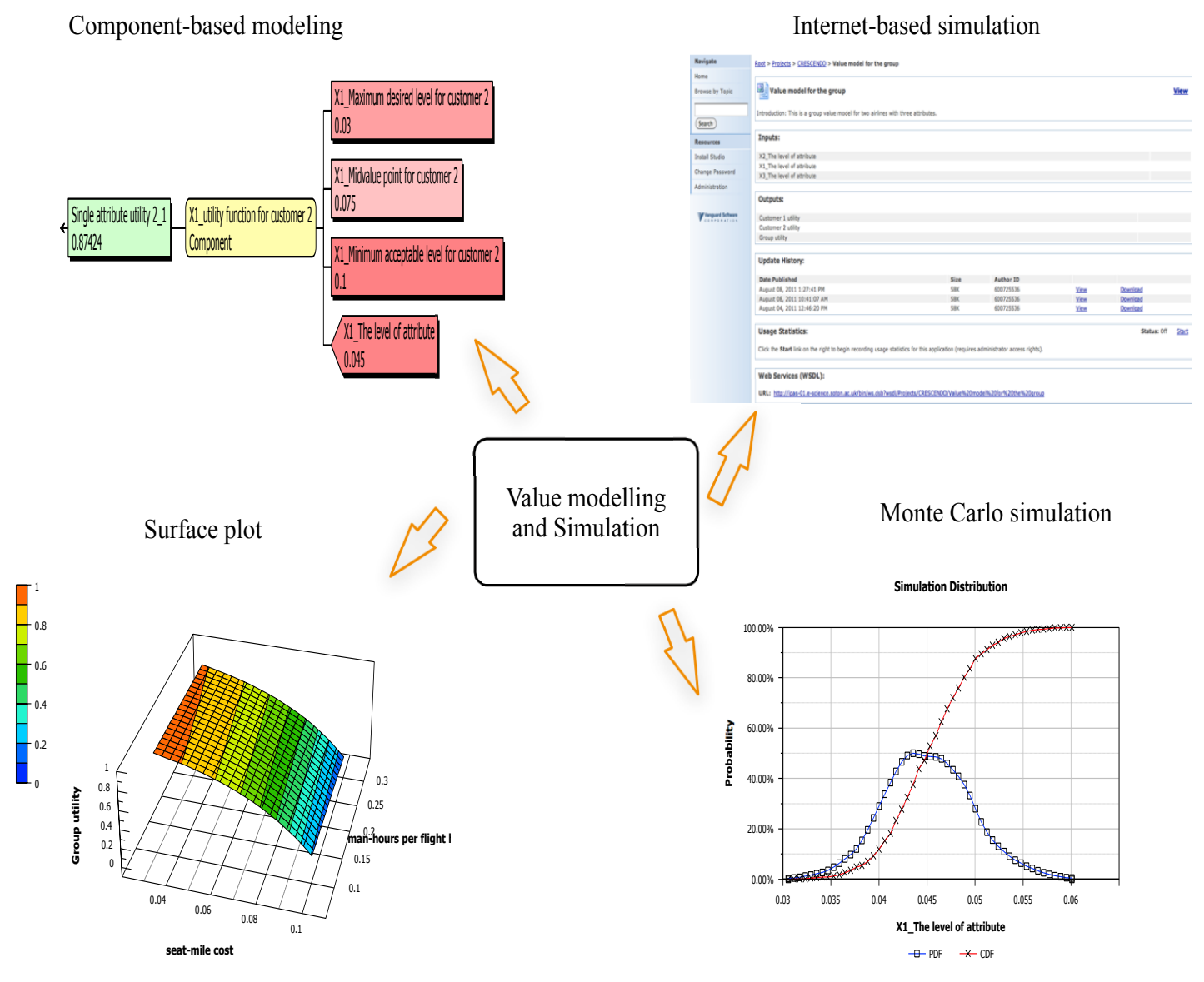

Figure 13. Value modelling and simulation

Component-based modelling enables the developed airlines' group value model to be embedded as a component in a more comprehensive model (In this case, aircraft value optimization cycle in Figure 2). For this application case, the value model can be conveniently integrated into existing engineering models in an Isight simulation process workflow when the interface between top-level aircraft requirements and customer attributes are available. Internet-based simulation enables the developed value model to be published on the Internet and airlines can use these models directly through Internet browsers. When some relevant parameters are inputted, the value of the aircraft is calculated. The graphical relationships between ECs and group utility is visualized though two-dimensional and three-dimensional graph (such as surface plot). The influences of uncertain achievement of ECs on group utility are implemented through Monte Carlo simulations.

Through this application of the approach to RE of commercial aircraft, airlines' group value model is constructed. There are several advantages over the traditional approach of RE:

(1) The approach helps to resolve the methodological problems of the traditional approaches, including P1, P2, P3 and P4. It also provides solution to identified industrial expectations, including E1, E2 and E3.

(2) Airlines' value perceptions can be explicitly qualified, quantified, modelled and simulated, 
which was presented through the case study in this section. This information was used to enable value-based RE of commercial aircraft. Therefore, value-based RE can be integrated into existing quantitative engineering models.

(3) Airlines' value models can be used to evaluate available or potential aircraft alternatives, when the necessary information of aircraft concept alternatives is collected. A scalar value is calculated for the set of information attributes of a specific aircraft alternative. This is a very attractive feature that enhances the decision-making process.

(4) Value dimensions and value models can be explicitly shared at the different development levels within the extended enterprise, which offers significant potential to enable the development of aircraft that are perceived by customer airlines to be of high value. This value-based information can be used for the conceptual orientation at all different development levels, when the validated technical requirements at these levels are not available yet. Therefore, the approach reduces development risks throughout the extended enterprise, and reduces the 'time to market' of new aircraft.

Compared with other analytical approaches for measuring customer satisfaction or design merit (De Poel 2007, Scanlan et al. 2011) the proposed approach uses utility as a common measurement. The aggregation rules corresponding to different independence assumptions among different incommensurable units are also mathematically shown. It is also capable of dealing with the uncertainties involved in the achievement of objectives, which is compatible with a variety of uncertainties of different natures in the design problems. We acknowledge that it is not a straightforward work to construct a value model consistently with airline preferences. Consistency checks are necessary to figure out possible inconsistencies. These inconsistencies are then be solved by referring back to airlines. Hence, this approach promotes consistency and value-informed decision-making.

Compared with DBD that focuses on applications of utility analysis in design evaluation and selection (Thurston 2001), the approach is different because it focuses on an earlier stage rather than design process itself. Thus, it is an exploration of multi-attribute utility theory to construct value models at RE stage.

Chen and her colleges $(2006,2007)$ reduce multi-attribute decision-making to profitbased design formulation, thus their formulation avoids the difficulties associated with weighting factors and multi-objective optimization. They also use discrete choice analysis (DCA) for demand model to avoid the impossibility of deriving group ranking from individual ranking. Rather than avoiding, the proposed approach confronts directly these difficulties. It is especially applicable when the number of customers or the type of customers is relatively small, and there is necessity to explicitly model customer values from product attributes (or ECs) to customer attributes to individual customer utility to group utility. When there are a relatively large number of customers, it would be difficult to model explicitly the value of each customer. In this situation, DCA-based DBD is more advantageous, which models directly from product attributes to group utility. But DCA-based DBD cause more workload when the set of attributes is large. 


\section{Conclusions}

Understanding customer needs and deriving requirements specification in terms of value is of subjective nature and necessitates logical process and methods for qualification and quantification. Some methodological problems remain unaddressed, such as the problems discussed in Section 2. Aiming to mitigate these methodological problems and rationalize the requirements establishment process, this paper presents a prescriptive approach to support value-based requirements engineering. The underlying rationales and foundations are listed in detail. They include the usage of objectives, means-ends analysis, part-whole analysis and multiattribute utility theory. Nothing is particularly new to engineering design communities, but we claim the approach does provide a prescriptive and logical way to understand customer needs in terms of value. The main contribution of this research is to derive value models from initial customer statements, which enables a progression of value-driven design from economic based value model to multi-dimensional value model, and some methodological problems are resolved.

However, it is not a trivial process to transform subjective, ambiguous customer statements into measureable customer values. More subjective inputs from customers are needed. It demands hard work and creative thinking about the value. This approach also requires more knowledge and skills from requirements engineers to enable its real function in practice.

\section{Acknowledgements}

We thank Anne Monceaux at EADS Innovation Works and Mario Kossmann at Airbus UK for numerous discussions about value modelling and simulation at requirements stage. The research leading to these results has received funding from the European Community's Seventh Framework Programme (FP7/2007-2013) (www.crescendo-fp7.eu) under grant agreement n॰234344.

\section{References}

Agouridas, V., Winand, H., McKay, A., and Pennington, A., 2006. Early Alignment of Design Requirements with Stakeholder Needs. Journal of Engineering Manufacture - Part B, 220(9), 1483-1507.

Agouridas, V., McKay, A., Winand, H., and Pennington, A., 2008. Advanced Product Planning: A Comprehensive Process for Systemic Definition of New Product Requirements. Requirement Engineering, 13(1), 19-48.

Bayus, B., 2007. Understanding Customer Needs. In: Shane, S. eds. Blackwell handbook of technology and innovation management, MA: Blackwell Publishes, Cambridge.

Bode, J., and Fung, R. Y. K., 1998. Cost Engineering with Quality Function Deployment. Computers \& Industrial Engineering, 35(3-4), 587-590.

Cheung, J., Scanlan, J., and et al. 2012. Application of Value-Driven Design to Commercial Aero-Engine Systems. AIAA Journal of Aircraft (in print).

Claros Salinas, M.P., Prudhomme, G., and Brissaud, D., 2008. Requirement-Oriented Activities in An Engineering design Process, International Journal of Computer Integrated Manufacturing, 21(2), 127-138.

Collopy, P., and Hollingsworth, P., 2009. Value Driven Design. In: Proceedings of the 9th AIAA Aviation 
Technology, Integration, and Operations Conference, Hilton Head, South Carolina.

De Chazelles, P., Comes, M., and Anne, K., 2004. Customer Focused Engineering in Airbus A380 Programme. In: Proceedings of INCOSE 14th Annual International Symposium on Systems Engineering.

De Poel, I. V., 2007. Methodological Problems in QFD and Directions for Future Development. Research in Engineering Design, 18(1), 21-36.

EIA 632, 1998. Processes for Engineering a System ANSI/EIA-632, EIA.

Franssen, M., 2005. Arrow's Theorem, Multi-criteria Decision Problems and Multi-Attribute Preference in Engineering Design. Research in Engineering Design, 16, 42-56.

Griffin, A., and Hauser, J. R., 1993. The Voice of the Customer. Marketing Science, 12(1), 1-27.

Harsanyi, J.C., 1955. Cardinal welfare, individualistic ethics, and interpersonal comparisons of utility. Journal of Political Economy, 63, 309-321.

Hauser, J. R., and Clausing, D., 1988. The House of Quality. Harvard Business Review, 66(3), 63-74.

Hazelrigg, G.A., 1998. A Framework for Decision-Based Engineering Design. ASME Journal of Mechanical Design, 120, 653-658.

Hazelrigg, G.A., 1999. An Axiomatic Framework for Engineering Design. Transactions of the ASME, 121, 342-347.

Hoyle, C., and Chen, W., 2007. Next Generation QFD: Decision-Based Product Attribute Function Deployment. In: Proceedings of the $16^{\text {th }}$ ICED, Paris.

Hoyle, C., Kumar, D., and Chen, W., 2006. Product Attribute Function Deployment (PAFD) for DecisionBased Conceptual Design. In: Proceedings of the 2006 ASME Design Engineering Technical Conference, Philadelphia, Pennsylvania.

Keeney, R. L., 1992, Value-Focused Thinking, Harvard University Press, Cambridge, MA.

Keeney, R. L., and Raiffa, H., 1993. Decisions with Multiple Objectives: Preferences and Value trade-offs. Cambridge University Press.

Keeney, R. L., 2004. Stimulating Creative Design Alternatives Using Customer Values. IEEE Transactions on Systems, Mans and Cybernetics-Part C: Applications and Reviews, 34(4), 450-459.

Keeney, R. L., and von Winterfeldt, D., 2007. Practical Value Model. In: Edwards, W., Miles, Jr., R., and von Winterfeldt, D., eds. Advances in decision analysis, Cambridge University Press.

Keeney, R. L., 2009. The Foundations of Collaborative Group Decisions. Internal Journal of Collaborative Engineering, 1(1-2), 4-18.

Mahashabde, A, et al, 2011. Assessing the Environmental Impacts of Aircraft Noise and Emissions. Progress in Aerospace Sciences, 47(1), 15-52.

Pahl, G., and Beitz, W., 2007. Engineering Design: A Systematic Approach, 3rd edition, Springer.

Scanlan, J., Woolley, M., and Eres, H, 2011. A Metric-Based Approach to Concept Design, (Unpublished manuscript).

Sen, A.,1970. Collective Choice and Social Warfare, Holden Day, San Francisco.

Thurston, D., 2001. Real and Misconceived Limitations to Decision Based Design With Utility Analysis. Journal of Mechanical Design, 123(2), 176-182.

Ulrich, K. and Eppinger, S., 2007. Product Design and Development, 4th edition, McGraw-Hill/Irwin Press.

Wang, M. and Zeng, Y., 2009. Asking the Right Questions to Elicit Product Requirements. International Journal of Computer Integrated Manufacturing, 22(4), 283-298.

Wassenaar, H.J., and Chen, W., 2001. An Approach to Decision-based Design. In: Proceedings of IDETC/CIE, Pittsburgh, Pennsylvania, USA.

Woodruff, R.B., 1997. Customer Value: The Nest Source for Competitive Advantage. Journal of the Academy of Marketing Science, 25(2), 139-153.

Zhang, X., Auriol, G., Monceaux, A. and Baron, C., 2011. A Value-Centric QFD for establishing Requirements Specification. In: Proceedings of the $18^{\text {th }}$ International Conference on Engineering 
Design, Copenhagen, Denmark.

Zhang, X., Auriol, G., Eres, H., Baron, C., and Kossmann, M., 2012. Understanding Airlines' Value Perceptions for Value-Based Requirements Engineering Of Commercial Aircraft. In: Proceedings of the INCOSE International Symposium, Rome, Italy.

Zhang, Z. and Chu, X., 2009. A New Integrated Decision-making Approach for Design Alternatives Selection for Supporting Complex Product Development. International Journal of Computer Integrated Manufacturing, 22(3), 179-198. 